\title{
Ironía trágica en Baquílides
}

\author{
Fernando GARCÍA ROMERO \\ Universidad Complutense de Madrid \\ fgarciar@ucm.es
}

Recibido: 14-11-2011

Aceptado: 15-12-2011

\section{RESUMEN}

Una de las cualidades más alabadas en la poesía de Baquílides es su talento narrativo, su habilidad para narrar una historia. Y un rasgo que sobresale en la técnica narrativa de Baquílides es el empleo de recursos propios del drama, entre los cuales se cuenta el tema objeto de este estudio: la «ironía trágica». Contando con la complicidad del auditorio, que, como ocurre en la tragedia, sabe lo que los personajes no saben, Baquílides juega hábilmente con las emociones de los oyentes, que entienden más de lo que los personajes dicen. Se estudia especialmente el final del relato mítico del epinicio 5 (Meleagro y Heracles).

Palabras clave: Baquílides, lírica coral, epinicio, ironía trágica, Meleagro, Heracles, Deyanira.

\begin{abstract}
Narrative talent is one of the most celebrated qualities in the poetry of Bacchylides. And an outstanding feature of the Bacchylidean narrative technique is the frequent use of dramatic devices. The aim of this contribution is to study one of these dramatic devices, «tragic irony». In complicity with the audience, who, as in tragedy, knows more than characters know, Bacchylides handles skilfully the emotions of his listeners, who understand more than characters say. We study above all the end of the myth of the fifth ode (Meleager and Heracles).
\end{abstract}

Key words: Bacchylides, tragic irony, choral lyric, epinician poetry, Meleager, Heracles, Deianeira.

No voy a comenzar diciendo nada original, sino una afirmación repetida constantemente por los estudiosos de Baquílides: que, desde la misma Antigüedad, como muestra un muy citado pasaje del tratado Sobre lo sublime $(33,5)^{1}$, nuestro poeta ha sufrido la «desgracia» de verse continuamente comparado y confrontado con un poeta de secular y consolidado prestigio como es Píndaro, y este hecho ha influido notablemente en la valoración de Baquílides, a menudo injusta; hasta el punto de que, como dejó dicho Jacques Péron, se tendía a afirmar que «cuando Baquílides es diferente de Píndaro,

\footnotetext{
${ }^{1}$ «¿Y qué? ¿En poesía lírica preferirías ser tú Baquílides más que Píndaro y en tragedia Ión de Quíos más que Sófocles, por Zeus? Pues los unos no cometen faltas y en su pulido lenguaje todo está escrito con bello estilo, y, en cambio, Píndaro y Sófocles a veces lo abrasan todo con su ímpetu, pero se apagan incomprensiblemente con frecuencia y caen en los defectos más desafortunados».
} 
es inferior a él, y cuando se asemeja a Píndaro, es porque lo plagia $»^{2}$. No han faltado, naturalmente, quienes hayan defendido una estimación más objetiva de la poesía de Baquílides, libre de ociosas comparaciones con el genio pindárico ${ }^{3}$, pero la afirmación de Péron es válida aún para trabajos muy posteriores e incluso de filólogos muy competentes como Ilja Pfeijffer, quien en su contribución a un volumen conmemorativo del centenario de la publicación del papiro de Baquílides ${ }^{4}$ se muestra de acuerdo con la afirmación de Charles Segal ${ }^{5}$ de que Baquílides «cuando ofrece lo peor de sí mismo, puede ser blandamente convencional», y preguntándose, a propósito del epinicio 10, ¿dónde hemos encontrado todas estas expresiones que nos suenan conocidas?, se responde Pfeijffer a sí mismo que «en Píndaro», y concluye que «parece que Baquílides se esfuerza por crear una atmósfera pindárica, lo cual es una conclusión sorprendente, pero no encuentro otra razón que explique la gran cantidad de vocabulario que toma prestado de Píndaro». Pfeijffer no se plantea siquiera la posibilidad de que sea Píndaro quien imite a Baquílides o de que se trate de convenciones del género que emplean los dos poetas ${ }^{6}$; necesariamente ha de ser Baquílides quien imite a Píndaro.

Hay, no obstante, al menos un aspecto de la poesía de Baquílides que siempre le ha sido alabado por los críticos, y es su talento narrativo, su maestría para narrar una historia ${ }^{7}$, aunque en ocasiones incluso esta cualidad ha servido para atacar al pobre Baquílides. Así, algunos han dicho que lo único que le interesa a nuestro poeta es contar una historia, aunque esa historia no tenga nada que ver con el resto del poema, lo cual es radicalmente erróneo ${ }^{8} ; \mathrm{y}$ otros han afirmado que Baquílides narra historias porque no tiene nada más que ofrecer: es un poeta superficial que, por ejemplo, nos describe minuciosamente cómo se ha producido el triunfo del atleta (cf. $10.21 \mathrm{ss}$.: el corredor, llevado de su impulso, se precipita sobre el público) $)^{9}$, mientras que Píndaro

${ }^{2}$ Péron (1978: 307-308).

${ }^{3}$ Cf. Stern (1970). Vease todavía Hutchinson (2001: 326): «here the false historical antithesis of an original Pindar and an unoriginal Bacchylides can lead with particular ease to an aesthetic misconception of Bacchylides»; y Fearn (2007: 341): «classical scholarship has generally sought to evaluate Bacchylides negatively by placing him side by side with Pindar and aestheticizing the poetry and separating it from the contexts in which it was originally commissioned...And, at the very least, I hope to have shown that reading and studying Bacchylides' poetry is a challenging, insightful, and thoroughly worthwhile activity». Véase al respecto Pfeijffer \& Sling (1999: 9-10).

${ }^{4}$ Pfeijffer (1999: 55-56).

${ }^{5}$ En las páginas que dedica a nuestro poeta en Easterling \& Knox (1995: I.1, 195-196).

${ }^{6}$ A esta posibilidad apunta, pienso que con razón, Rossi (1995: 186): «Si è parlato molto di influenza di Pindaro, ma spesso si tratta soltanto di una parentela di genere e di tematica: è possibile, anzi è probabile, che paralleli di questo tipo non siano prova di dipendenza».

${ }^{7}$ Véanse al respecto Carne-Ross (1962), Kirkwood (1966), Segal (1976), Rengakos (2000), Pfeijffer (2004), Fearn (2007: 122 ss.).

${ }^{8}$ Así, Croiset (1898: 13): «il est visible que le talent de Bacchylide s'attache plus à la beauté des morceaux pris à part qu'à l'unité profonde de l'ensemble»; Mallinger (1899: 21 ss.): «il aime les morceaux brillants pour eux-mêmes, sans trop de sourcier de leur rapport avec le sujet»; también Van Groningen (1960²: 199). Cf. Pfeijffer \& Sling (1999: 9), y también, para una refutación de estas posturas, García Romero (2002), Pietsch (2003).

${ }^{9}$ Cf. Rossi (1995: 183): «ma fermi restando come elementi costitutivi [dell'epinicio] l'occasione, il mito e la gnome, Bacchilide si diffonde con più continuità ed estensione nella narrazione del mito, e nelle sezioni dedicate all'attualità dà uno sguardo più attento alla prestazione sportiva e alla celebrazione della festa». 
está interesado no en describirnos la competición ${ }^{10}$ sino en reflexionar acerca de lo que significa la competición en la escala de valores de la sociedad, para ofrecernos una «filosofía del deporte», que no encontramos en Baquílides ${ }^{11}$.

En fin, yo no sé si Baquílides es tan superficial y Píndaro tan profundo (quizá sí, pero en todo caso no me parece que eso sea lo más importante para quien estudia su poesía, tal como señalan, por ejemplo, Suárez de la Torre, Rossi o Carey ${ }^{12}$ ); pero lo que sí sé, o al menos creo saber, es que a Baquílides, efectivamente, le gusta contar historias, en él brilla, por decirlo con palabras de Gennaro Perrotta, esa «gioia ionica del raccontare $\rangle^{13}$ que caracteriza igualmente la obra de Heródoto.

Un rasgo que sobresale en la técnica narrativa de Baquílides es el empleo muy frecuente de recursos propios del drama. Quienes han estudiado cómo narra Baquílides sus mitos suelen destacar la habilidad con la que nuestro poeta combina la narración fluída y las escenas de diálogo dramático, una combinación que, dentro de la poesía lírica, recuerda mucho más a Estesícoro que a Píndaro ${ }^{14}$ y que, por supuesto, muestra

${ }^{10}$ Pfeijffer (1999: 58): «The only narrative passage in the ode [10] is to be found in the first epode, where the victor's athletic achievement is described graphically. This is something Pindar never does. It has been noted that, «for a poet who is stimulated by a specific event, Pindar is remarkable for his reluctance to describe the victory which occasions the ode» [Ch. Carey]. Vivid descriptions of the contest itself, so familiar to us from our modern media, do not occur in Pindar's odes».

${ }^{11}$ Véase al respecto el agudo análisis de Bernardini (1980). Cf. también Bowra (1964), Fernández Galiano (1971), García Romero (1992).

${ }^{12}$ Suárez de la Torre (1988: 231): «Por otra parte, la acusación de "simplicidad" contra Baquílides frente a la "profundidad" pindárica no tiene en cuenta que estamos ante una de las posibles utilizaciones de unas características de estilo y de técnica de composición que permiten direcciones diferentes sobre una pauta básica. Píndaro y Baquílides comparten recursos genéricos que no suponen uniformidad. Por ejemplo, es totalmente cierto que el carácter "impresivo" de la poesía baquilidea se basa en rasgos como la estructura paratáctica, las construcciones más breves, la mayor tendencia a la repetición de palabras o conceptos, etc.; pero esto no debe despreciarse como "superficial" o "falta de maestría". Tales reproches revelarían falta de comprensión de la técnica poética coral por quien los emitiera».

Rossi (1995: 183): «Come rappresentante di una stessa funzione letteraria, [Bacchilide] è diverso dai due poeti [Simonide e Pindaro] quasi contemporanei: non certo innovatore come Simonide, né grandioso e quasi invasato come Pindaro. Ma è poeta che remunera ampiamente chi vada in cerca di alcune qualità come eleganza e leggerezza di tocco descrittivo. E, in più, con le sue qualità caratteristiche ci dà ancora una volta una misura della varietà di soluzioni personali nell'ambito di generi pur molto formalizzati come l'epinicio e i canti religiosi».

Carey (1999: 27-28): «But beyond their function within the rhetoric of praise, these effects emphasise the themes of human ignorance, the opacity of destiny, the importance of piety, and lend the odes a didactic quality which recommends the victor and the ode to wider audiences with no interest in the victor as an individual, ensuring the survival of the poet's praise. It is here that the victory odes and the "dithyrambs" converge, for the non-athletic songs show the same interest in moral choice (Odes 15, 17), in destiny (Ode 16), and in the impossibility of fully understanding the world (Odes 15, 16, 17, 18). There is nothing in these concepts which is new. However, didacticism in Greek poetry is not necessarily to be understood... as the presentation of new knowledge; it is more often to be found in the (re)presentation of shared values. Bacchylides' insight into the working of the world is not remotely new, but it is as profound as anything to be found in Greek literature».

${ }^{13}$ Cf. Del Grande (1956: 128).

${ }^{14}$ Cf. Rossi (1995: 186), Robbins (1997: 280 y 283-284), Hutchinson (2001: 326), Rengakos (2000: 108), Fearn (2007: 20 ss.). 
afinidades con el diálogo de la tragedia, como han señalado numerosos estudios ${ }^{15}$. A este respecto, es quizá especialmente significativo el caso del ditirambo 18 , todo él un vívido diálogo dramático entre coro y solista (o entre dos semicoros), a propósito del cual se ha discutido si es un recuerdo de los antiguos ditirambos que dieron paso a la tragedia o bien se trata de un poema influído por la ya consolidada tragedia ateniense. Quizá merezca la pena recordar que, un siglo después, Platón (República III 394c) ${ }^{16}$ cita el ditirambo como ejemplo de género narrativo, en el cual es el propio poeta el que hace la narración, por oposición al género «completamente imitativo» representado por la tragedia y la comedia; en cambio, en el ditirambo 18 de Baquílides falta absolutamente la narración del poeta y todo el poema es «imitativo», como la tragedia.

Son muchos quienes han estudiado este interesante tema. Mi propósito ahora es analizar otra técnica «dramática» que Baquílides maneja, en mi opinión, con brillante habilidad y que no ha sido muy estudiada: lo que se ha dado en llamar la «ironía trágica». Contando con la complicidad del auditorio, que, como ocurre en la tragedia, sabe lo que los personajes no saben, Baquílides juega hábilmente con las emociones de los oyentes, tal como ha indicado Chistopher Carey ${ }^{17}$ : «Baquílides es capaz de provocar efectos emocionales por medio de alusiones, sin narrar los hechos, jugando con lo que el público sabe.....Consigue jugar hábilmente con las emociones de los oyentes, implicando a su audiencia, cuando hace que los más potentes efectos emotivos se consigan no por lo que cuenta, sino por lo que calla: es la mente del oyente, no la narración de los hechos, lo que provoca esos efectos......Así, la audiencia se convierte en colaborador activo, no en receptor pasivo, lo cual es, como nota Teofrasto (fr.696 Fort.), un efecto más emotivo que lógico» ${ }^{18}$. Quizá sea el final del mito del epinicio 5 el ejemplo más claro de este «arte alusivo» de Baquílides, mediante el cual nuestro poeta consigue que el público entienda bastante más de lo que los personajes dicen.

El largo relato mítico del epinicio 5 (vv.56-175) narra el descenso de Heracles al Hades en busca de Cérbero y su encuentro con la sombra de Meleagro. El núcleo central del mito es el extenso relato que hace Meleagro de las circunstancias que provocaron su muerte, durante la cacería del jabalí de Calidón, y que conocemos bien desde el canto IX de la Ilíada: una vez muerto el jabalí, tiene lugar una violenta batalla entre los etolos y los curetes, durante la cual Meleagro da muerte a los hermanos de su madre Altea, la cual, en venganza, quema el leño al que estaba ligada la vida de su hijo; en efecto, cuando Meleagro había cumplido siete días, las Moiras predijeron a Altea que su hijo moriría si el leño que en aquellos momentos ardía en el fuego se consumía totalmente ${ }^{19}$; Altea lo cogió de inmediato y lo guardó en un cofre, de donde ahora lo saca

${ }^{15}$ Véase al respecto Kirkwood (1966), Burnett (1985: 111-128), Suárez de la Torre (1988: 229), Pfeijffer (1999).

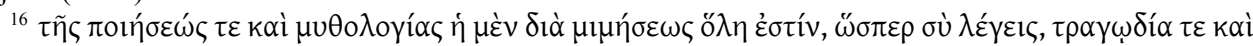

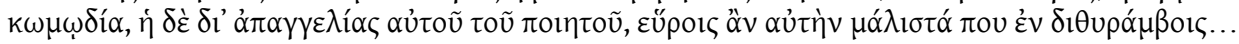

${ }^{17}$ Carey (1999: 23-24 y 27-28). Sobre la ironía en Baquílides, véase tambien Stern (1970: 294).

${ }^{18}$ Esa «implicación emotiva del público» que tanto gusta a nuestro poeta se manifiesta también en otro aspecto: en sus epinicios Baquílides, para encarecer la alabanza del atleta, recurre con gran frecuencia al aplauso del público o a su intervención (3.9 ss.; 5.48-49; 9.30 y 35; 10.21 ss.; 11.17 ss.).

${ }^{19}$ Cf. Wulff Alonso (1997: 176 ss.), con bibliografía. 
para que acabe de quemarse, lo cual provoca la muerte de su hijo en plena juventud. Baquílides acaba su relato de la siguiente manera (vv.159-175):

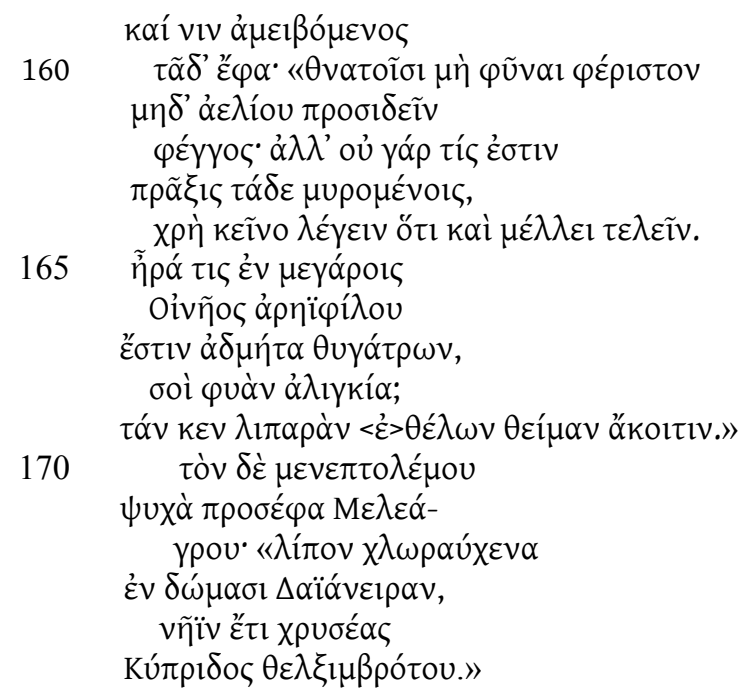

Y respondiéndole (Heracles) dijo así: «Para los mortales no haber nacido es lo mejor, y no haber visto la luz del sol. Pero, ya que nada aprovecha lamentarse por ello, es preciso hablar de lo que realmente ha de cumplirse. ¿Hay acaso en los palacios de Eneo, caro a Ares, alguna de sus hijas aún no casada, a ti en su porte semejante? De buen grado la haría mi brillante esposa». Y a él contestó el alma de Meleagro firme en la guerra: «En casa dejé a Deyanira de fresco cuello, ignorante aún de la áurea Cipris que encanta a los mortales».

En este punto Baquílides interrumpe bruscamente su relato (no se vuelve a mencionar la misión que ha llevado a Heracles al Hades, la captura de Cérbero) ${ }^{20}$, y aunque esta repentina interrupción ha sido censurada por diversos comentaristas, yo comparto la opinión de quienes la consideran un gran acierto por parte de nuestro poeta ${ }^{21}$. Todo el relato de Meleagro está teñido de un melancólico pesimismo, que, aparentemente, se convierte al final en un cierto optimismo, cuando Heracles, impresionado por la figura de Meleagro, considera que una hermana suya sería la esposa adecuada para él. Pero este optimismo es sólo aparente, ya que precisamente la brusca interrupción del mito termina dejando en el oído del auditorio el inquietante nombre de Deyanira ${ }^{22}$, así

${ }^{20}$ El abrupto final del mito queda subrayado por el empleo de lo que Schadewaldt (1928: $267 \mathrm{ss}$.) llamó una «fórmula de ruptura» («Abbruchsformel»), que marca el paso a la última sección, no mítica,

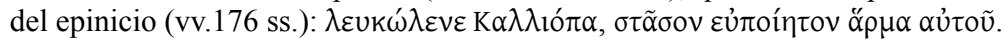

${ }^{21}$ Cf. Goldhill (1983: sobre todo 77), García Romero (1987: 356 ss.), Platter (1994: 343), Rutherford (1997: 55), Rengakos (2000: 105).

${ }^{22}$ Cf. Péron (1978: 324), Morin (2007: 34: «mais la simple nomination, par Méléagre, de Déjanire permet au poète de suggérer le sort qui attend Héraclès, sort qui double, ou réitère en réalité, celui de Méléagre»). 
como claras alusiones al trágico destino de Heracles, que el público, conocedor del final de la historia, comprende fácilmente.

En efecto, prácticamente todas las palabras del breve parlamento final de Meleagro tienen doble sentido para los espectadores. Empecemos por lo que nos parece más evi-

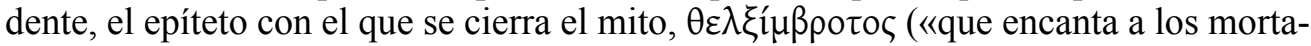
les»), que califica a Afrodita. El epíteto es quizá una creación de nuestro poeta, y en la literatura posterior se documenta únicamente en un poema órfico (Orph.L. 320, donde

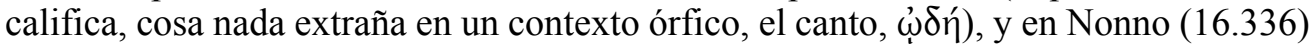
como epíteto de Dioniso; no obstante, es posible que este compuesto apareciera también en otro pasaje del propio Baquílides, concretamente en el v.12 del ditirambo 25 , titulado precisamente Meleagro ( $\theta \varepsilon \lambda] \xi$ j́ $\mu \beta \rho o \tau o \zeta)$, aunque la ausencia de contexto nos impide saber nada más sobre su sentido. En todo caso, su empleo como calificativo de Afrodita no es en absoluto extraño, ya que la raíz del verbo $\theta \varepsilon ́ \lambda \gamma \omega$ se dice a menudo de la acción de Eros para describir el poder fascinador del amor sobre los mortales ${ }^{23}$. Así, dentro un contexto que nos interesa especialmente por razones obvias, en Las traquinias de Sófocles (vv.354-355) el mensajero relata a Deyanira que fue Eros «el

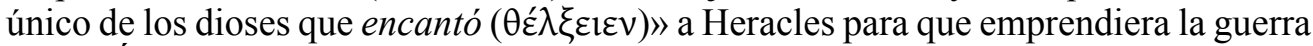
contra Éurito con el propósito de conquistar a Yole ${ }^{24}$ :

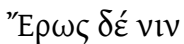

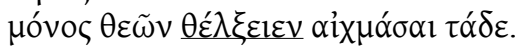

Y en Bacantes 402ss., en un pasaje lírico, leemos:

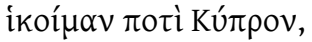

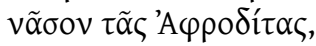

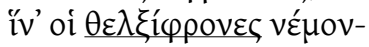

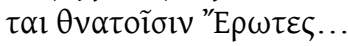

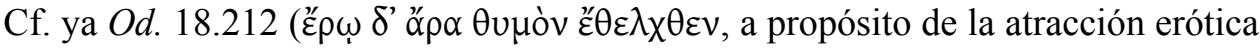
que experimentan los pretendientes a la vista de Penélope), y también Aesch. Supp.

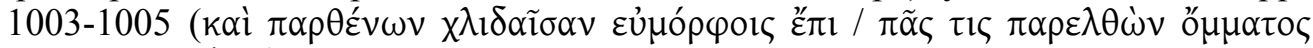

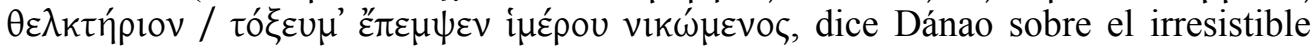
atractivo erótico que suscitan las vírgenes en quienes posan en ellas su mirada) y

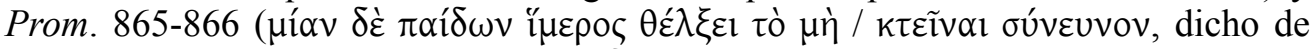
Hipermestra), Eur. Hipp. 1274 ( $\theta \varepsilon \dot{\lambda} \gamma \varepsilon \varepsilon$ l $\delta$ " E $\rho \omega \varsigma$, en un himno a Afrodita), A.R. 3.3-5

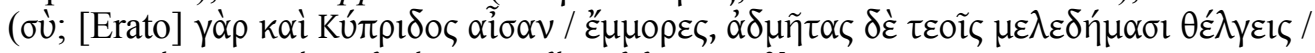

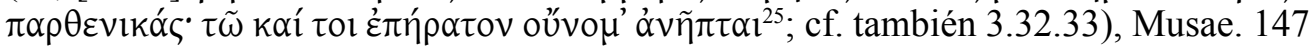

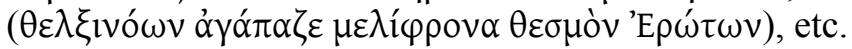

${ }^{23}$ Cf. Barret (1964: 393, ad v.1274), Kamerbeek (1970: 96, ad v.355), Müller (1980: 17 nota 43), Cassanello (1993: 71), Calame (2002: 53), Pérez (2000: I 296).

${ }^{24}$ Cf. Douterelo (1997: 198 y 203).

${ }_{25}$ «Pues tú tienes asignada la suerte de Cipris y encantas con tus cuitas a las jóvenes vírgenes que aún no conocen el yugo. Por eso se te da ese nombre amoroso». Cf. Hunter (1989: 97). 
Pero en nuestro pasaje, para el oyente que conoce el trágico final del matrimonio entre Heracles y Deyanira (los celos llevan a Deyanira a utilizar un encantamiento para recuperar el amor de Heracles, el cual acaba provocando la muerte del héroe),

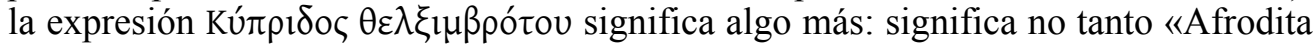
que encanta, que fascina a los mortales» como «Afrodita que con sus encantamientos destruye a los mortales». Porque, efectivamente, la raíz del verbo $\theta \varepsilon ́ \lambda \gamma \omega$ se emplea muy a menudo para designar encantamientos mágicos, muchas veces encantamientos eróticos ${ }^{26}$. Así, de nuevo en Las traquinias de Sófocles Deyanira afirma (vv.584-585):

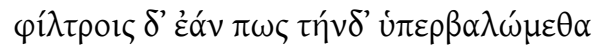

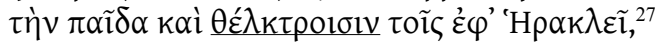

Y en el Hipólito de Eurípides la nodriza, tratando de ayudar a Fedra, le dice (vv. 509510):

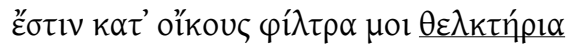

है $\rho \omega \tau$ то,

Cf. igualmente $A P 6.88$ (de Antífanes):

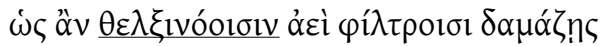

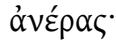

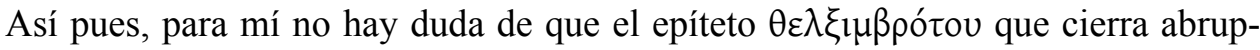
tamente el mito del epinicio 5 deja en los oyentes no una esperanza positiva, como pretende Heracles, sino una clara alusión al posterior destino trágico del héroe, sobre todo si tenemos en cuenta que previamente Meleagro le ha narrado su propia muerte, provocada igualmente por medio de artes mágicas.

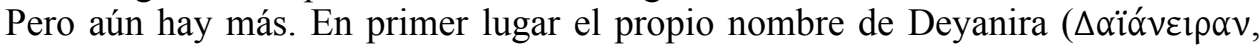
v.173) es ya todo un presagio, dado que puede significar «la que mata (o hace arder) a su marido»o $\mathrm{O}$ «matadora de hombres» ${ }^{28}$. Además, en el contexto de nuestro epinicio este posible juego etimológico con el nombre de Deyanira puede ser especialmente significativo. En primer lugar, porque nuestro poeta quizá haya jugado ya, y en un sentido similar, con el nombre de Meleagro en los vv.122-124, cuando afirma, justo antes de narrar la muerte de Meleagro,

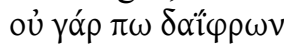

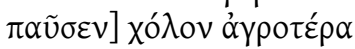

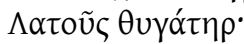

\footnotetext{
${ }^{26}$ Sobre el tema, véase Faraone (1999).

${ }^{27}$ «Y si de alguna manera con prácticas mágicas para atraer el amor y con encantamientos usados con (contra) Heracles puedo aventajar a la muchacha».

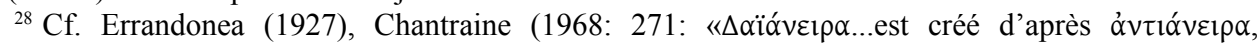

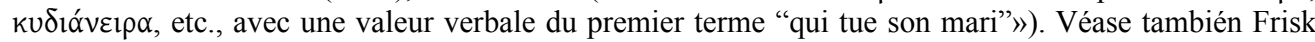
(1960-1972: I 377).
} 
Como ya indica Proclo en su comentario al Crátilo platónico ${ }^{29}$, el nombre de Me-

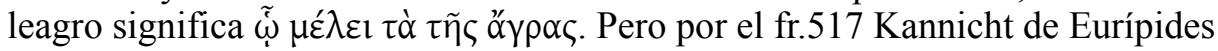

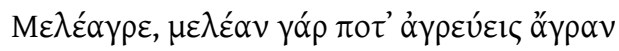

sabemos que el nombre de Meleagro, por etimología popular creada a partir de las circunstancias de su muerte, era interpretado en el sentido «desgraciado en la caza». Es

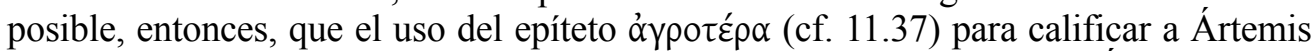
sea algo más que el simple empleo de un epíteto cultual que presenta a Ártemis como diosa de los animales salvajes, y que esconda una irónica alusión a la muerte de Meleagro precisamente en la caza (ó $\gamma \rho \alpha$ ) de un animal salvaje enviado por Ártemis (unas circunstancias, recordémoslo, que Heracles no conoce, pero los oyentes sí) $)^{30}$. Pero es que, en segundo lugar, la posibilidad de que Baquílides esté jugando con el significado del nombre de Deyanira al final de su relato (recordando a los oyentes que esa Deyanira con la que querría casarse va a ser quien cause su muerte) se refuerza por el hecho de que

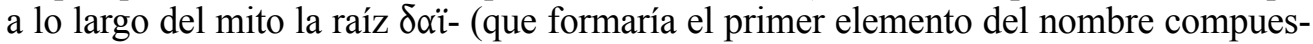
to «Deyanira») ha tenido connotaciones funestas, en concreto en el epíteto $\delta \alpha i ̂ i \varphi \rho \omega v$, que ha calificado a Ártemis en el v.122 y a Altea en el v.13731. Evidentemente, de los dos sentidos en los que la tradición poética griega utiliza el adjetivo $\delta \alpha i ̂ ́ \varphi \rho \omega v$ (por un lado «sabio, prudente», vinculado al verbo $\delta \alpha \tilde{\eta} v \alpha l$, y por otro «que piensa destruir, de

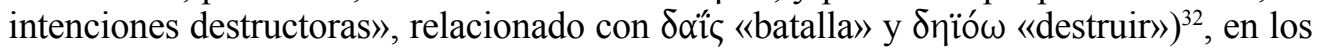
dos pasajes que hemos citado prevalece este segundo sentido; así, Baquílides utiliza los

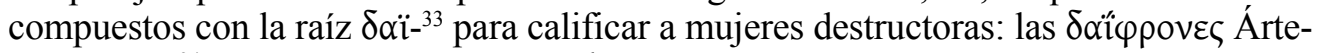
mis y Altea ${ }^{34}$ matan a Meleagro, y $\Delta$ aióóveı $\alpha$ será la causante de la muerte de Heracles. Es posible que nuestro poeta vuelva a jugar con el significado del nombre de Deyanira en el fr. 64, de atribución dudosa: en el relato del episodio de Deyanira, Heracles y

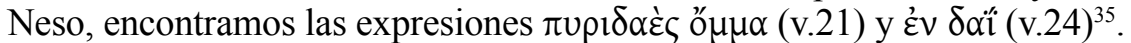

Deyanira es calificada en nuestro pasaje con el epíteto $\chi \lambda \omega \rho \alpha u ́ x \eta v$, que se documenta únicamente aquí y en el fr.586.2 Page de Simónides, dicho del ruiseñor (cf.

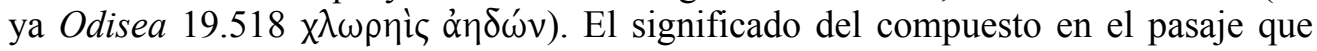
comentamos ha sido muy discutido:

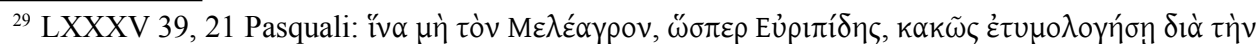

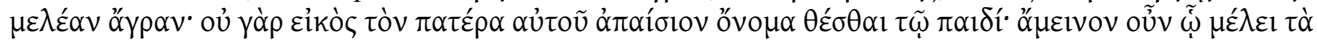
$\tau \tilde{\eta} \varsigma$ ăypac. Cf. Chantraine (1956: 45-46).

${ }^{30}$ Cf. Brannan (1972: 242-243).

${ }^{31}$ Cf. Brannan (1972: 256), Lefkowitz (1976: 69), Finn (1980: 237), Burnett (1985: 143-144), March (1987: 50 ss.), García Romero (1987: 331 y 337).

${ }^{32}$ Para Chantraine (1968: 248) el segundo sentido es probablemente el original, mientras que Frisk (1960-1972: I 342) sostiene lo contrario. Cf. Lefkowitz (1976: 63) y Brannan (1972: 242), quien considera posible que nuestro poeta esté jugando con el doble sentido del compuesto, aunque prevalezca «de mente destructora». Sobre el término, véase Führer (1991). Gerber (1984) traduce el término en el epinicio 5 por «hostile».

${ }_{33}^{33}$ Para nuestros efectos, no importa si la raíz que encontramos en $\Delta \alpha$ äóvelpo es la misma que la del adjetivo $\delta \alpha i ̂ ́ \varphi \rho \omega v$; lo importante es que para los oyentes se trata de la misma raíz.

${ }^{34}$ Cf. Burnett (1985: 143-144), Cummins (1993: 261).

${ }^{35}$ Cf. Platter (1994: 343). 
- Para unos pocos (Marindin, Irwin) sería una referencia al temblor de la garganta mientras se canta, una interpretación que, en nuestra opinión, se basa únicamente en su hipotético significado en el fragmento de Simónides ${ }^{36}$. Nosotros, al menos, no encontramos razón por la que en nuestro contexto se quieran alabar las habilidades musicales de Deyanira ${ }^{37}$.

- Más verosímilmente, otros (Del Grande, Maehler, Irigoin-Duchemin-Bardollet) ${ }^{38}$ consideran que en nuestro contexto el adjetivo indica color: Deyanira sería «la de pálido cuello».

- Finalmente, para la mayoría de los intérpretes (Jebb, Taccone, Van Leeuwen, Mrose, Edmonds, Liddell-Scott, Kriegler, Lefkowitz, Segal, Stern, Brannan, Finn, García Romero, Svarlien, etc. $)^{39} \times \lambda \omega p o ́ s$ significa aquí, como tan frecuentemente, «verde» por oposición a «seco», es decir, «fresco», de manera que Meleagro utilizaría $\chi \lambda \omega \rho \propto u ́ x \eta v$ como una referencia a la juventud de su hermana Deyanira, llamada aquí «la de fresco (i.e. joven) cuello».

En mi opinión, es ésta última la interpretación correcta y no creo probable que en nuestro pasaje $\chi \lambda \omega \rho$ ó́ indique color, en concreto la palidez de Deyanira (al menos en la intención con la que Meleagro utiliza el término para describir a su hermana). Herwig Maehler, para defender el sentido «la de pálido cuello» afirma que la palidez es el ideal de belleza femenina entre los antiguos; pero - pienso que significativamentecita en apoyo de su interpretación únicamente textos en los que ese color bello que se

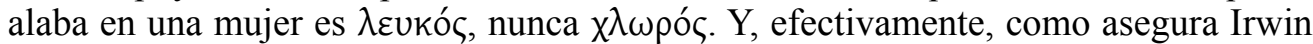

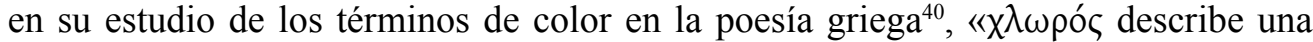
palidez enfermiza, no la "piel luminosa" admirada en una mujer...y censurada en los hombres...Para eso se emplea $\lambda \varepsilon \cup \kappa o ́ \varsigma$, para describir tanto calidad como color», añadiendo más adelante a propósito concretamente de nuestro pasaje que $\chi \lambda \omega \rho \alpha u ́ x \eta v$ «debe entenderse naturalmente como un elogio, no como referencia a una insana palidez». Y efectivamente, cuando se dice de personas, $\chi \lambda \omega \rho$ ó $\varsigma$ no se emplea como un elogio, sino que hace referencia a una palidez insana, causada, por ejemplo, por una enfermedad (cf. Thuc. 2.49.5, Hipp. Progn 2.4.6) y también por los efectos turbadores

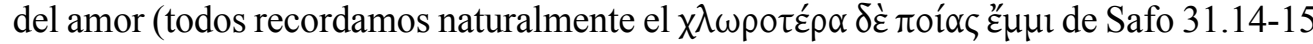
Voigt), o bien por los efectos del miedo, como atestiguan ya los versos de Homero ${ }^{41}$ :

${ }^{36}$ Cf. Manieri (1994), Barrigón (2003: 62).

${ }^{37}$ Maehler (1997) añade que, además, aủxńv significa «cuello» y no «garganta»; cf. Führer (1979).

${ }^{38}$ Del Grande (1963: ad loc.), Maehler (1982: ad loc.), Irigoin-Duchemin-Bardollet (1993: ad loc.).

${ }^{39}$ Jebb (1905), Taccone (1907), Van Leeuwen (1903), Morse (1902: 55), Edmonds (1927), Kriegler (1969: 12), Lefkowitz (1969: 86), Segal (1990: sobre todo 10), Svarlien (1995). Sobre el uso de $\chi \lambda \omega \rho o ́ \varsigma$ en el sentido de «fresco», véanse también Gómez Segura (1994) y Resinski (2000).

${ }^{40}$ Irwin (1974: 31-78; las citas en pp.64-65 y 73). Un espléndido estudio sobre $\chi \lambda \omega \rho o ́ \varsigma$ puede encontrarse en Fernández Colinas (1994: 818 ss.). Sobre el elogio de la belleza del cuello de una mujer, véase

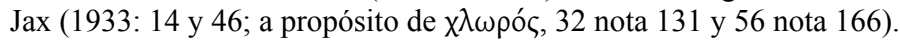

${ }^{41}$ Cf. Irwin (1974: 62 ss.), Handschur (1970: 150-156), Lefkowitz (1969: 86), Lorenzoni (1994). Lorenzoni comienza su pormenorizado estudio con una cita de Eustacio (812, 47-59, ad Il. 10.376) que

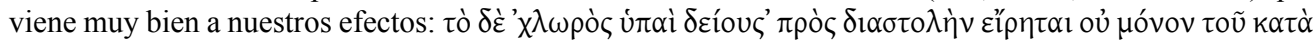

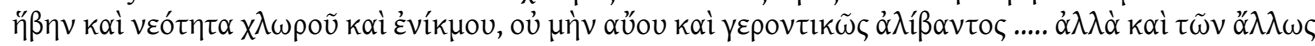

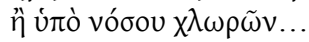




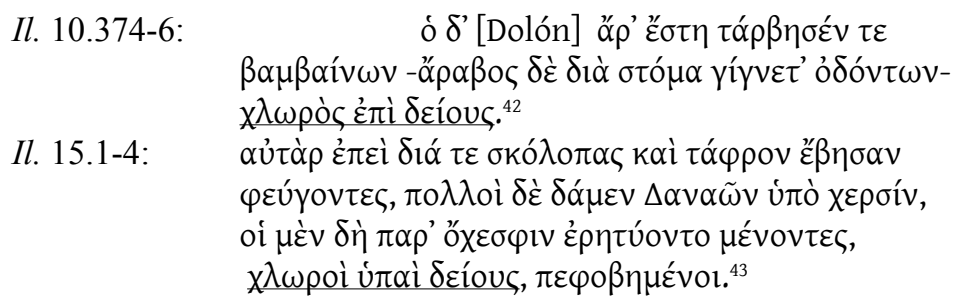

No es de extrañar, por lo tanto, que ya desde los poemas homéricos $\chi \lambda$ epíteto del miedo, a menudo del miedo que se siente ante la cercanía de la muerte

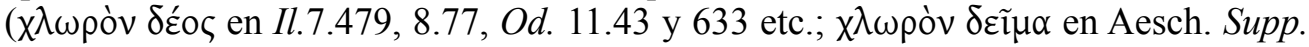

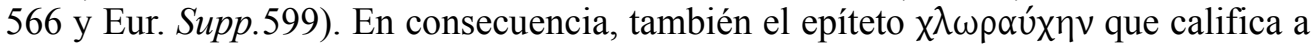
Deyanira y que en principio tiene un significado positivo (sea cual sea ese significado), creo que es posible que adquiera un doble sentido funesto, una nueva alusión al terrible final que aguarda a Heracles por obra de Deyanira. El recuerdo del «pálido miedo» homérico bien podría estar presente en un poema lleno de epicismos y que tiene, por supuesto, el canto IX de la Ilíada ${ }^{44}$ como referencia central para el relato de la historia de Meleagro.

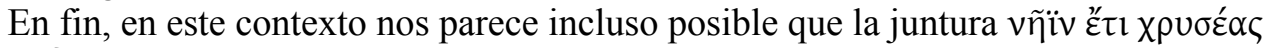

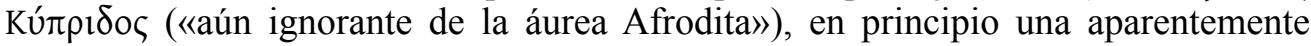
inocente expresión para hacer referencia a una muchacha soltera como Deyanira ${ }^{45}$, no sea tan inocente como parece y esconda un segundo sentido: «ignorante aún de la fuerza, del poder de la diosa» que, a través de ella, va a destruir a Heracles.

Y cabe incluso plantearse si las dos únicas palabras a las que aún no hemos hecho

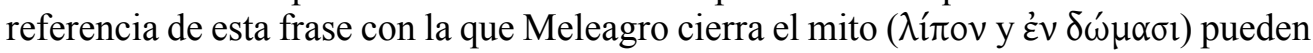
esconder también un segundo sentido funesto, concretamente dentro del mito tal como lo ha relatado Baquílides. Para mí es bastante evidente que Baquílides, como Píndaro y otros poetas, recurre habitualmente a la repetición de palabras para establecer vínculos (sea de manera explícita, sea de manera alusiva) entre diversas partes y situaciones

${ }^{42}$ «Se detuvo, presa del terror, balbuciendo (los dientes le castañeteaban en la boca) y pálido de espanto» (trad. de E. Crespo).

${ }^{43}$ «Mas cuando (los troyanos) franquearon la empalizada y la fosa en su huida, y muchos habían sucumbido a manos de los dánaos, se fueron deteniendo junto a los carros y permanecieron allí, pálidos de espanto y presas del pánico» (trad. de E. Crespo).

${ }^{44}$ Cf. García Romero (1987: 316 ss.), con bibliografía.

${ }^{45}$ En un fragmento atrubuido con dudas a Baquílides (64.10) y en el que se narra el episodio de He-

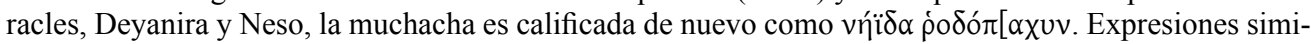

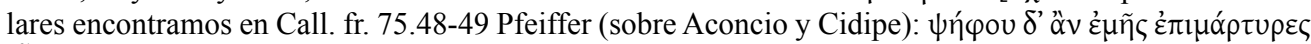

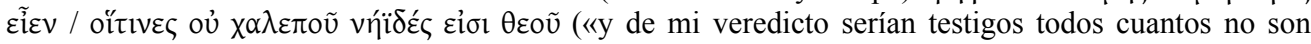

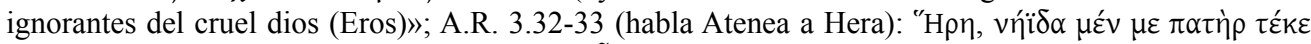

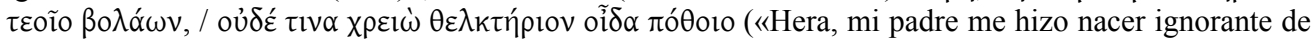
los tiros de Eros, y tampoco cosa alguna conozco que propicie el deseo»; cf. 3.129-130, Afrodita a Eros:

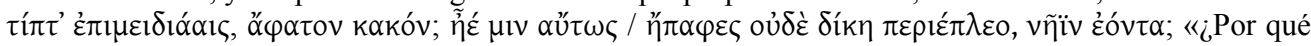
encima te ríes, pillo inefable? ¿Es que, como sueles hacer, lo engañaste, y con trampas lo has ganado,

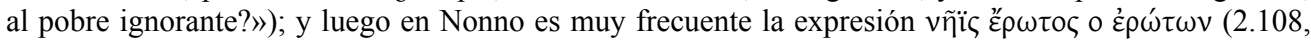
$3.103,11.558,15.376$ y $442,20.156,33.324,48.198,243$ y 465$)$. 
heroica, víctimas de los hechizos que contra ellos utilizan mujeres ${ }^{50}$ unidas a ellos por lazos de parentesco (Altea y Deyanira), que hacen que se cumpla así su destino. Y este paralelismo entre Heracles y Meleagro sería aún mayor si suponemos que Baquílides no está siguiendo la versión que luego haría especialmente popular Sófocles en Las traquinias (en la cual Deyanira causa la muerte de Heracles de manera involuntaria, sin querer hacerlo), sino una posible versión más antigua según la cual Deyanira, igual que Altea cuando causa la muerte de Meleagro, sabe lo que hace cuando impregna de veneno la túnica que va a vestir Heracles y lo mata con plena conciencia de sus $\operatorname{actos}^{51}$. Es posible, en efecto, que el público que asistía a la representación del epinicio 5 tuviera en mente no la Deyanira de Sófocles (una mujer tímida y dulce, que quizá sea creación del poeta trágico) sino una Deyanira enérgica y apasionada, una mujer más del tipo de Medea $^{52}$ (que podría haber dicho, como la Medea de Eurípides,

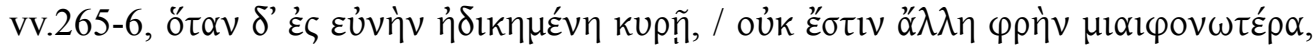
precisamente cuando se dispone a enviar a su rival el vestido empozoñado); una Deyanira, por tanto, mucho más parecida a su madre Altea (recuérdese, y puede ser otro rasgo irónico más en el relato de Baquílides, que Heracles pregunta a Meleagro

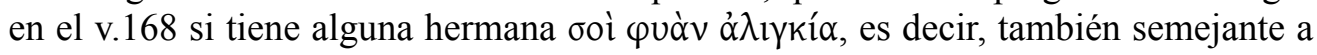
su madre). Y quizá esta intención de enfatizar el paralelismo entre Altea y Deyanira

${ }^{50}$ Muchos de los autores citados hasta aquí insisten en el tema de la «mujer destructora» en nuestro poema; véase también Plácido (1994).

${ }^{51}$ Se ha discutido mucho si la Deyanira de Sófocles es, como creen la mayoría de los estudiosos, una mujer dulce e inocente, o bien, según otros (Errandonea, Morin), una mujer apasionada que sabe muy bien lo que está haciendo cuando envía a Heracles la vestidura envenenada. Y también se ha discutido si, como querían Jebb (1892: XXXI-XXXII), Stoessl (1945) y otros, la Deyanira «dulce» es una creación de Sófocles o bien existía en la tradición anterior y habría sido recogida por Baquílides en su ditirambo 16. En todo caso, parece que en origen Deyanira era una muchacha «amazónica», amante de la guerra y de los carros, tal como reaparece posteriormente en D.S. 4.16.3 y Apollod. 1.8.1, y este hecho explicaría su nombre («la matahombres»), después interpretado en el sentido de «la que mata a su marido» cuando el personaje se liga a Heracles (Jebb). Para un tratamiento de estos problemas, véanse Pozzi (1996); March (1987: 47-77), para quien quizá esa Deyanira «amazónica» se encontrara ya en Hesíodo, fr. 25.14-25 (se menciona explícitamente el uso de venenos por parte de Deyanira para provocar la muerte de Heracles); Morin (2007), para quien en el fragmento de Hesíodo Deyanira mata a Heracles sabiendo lo que hace y piensa que de la misma manera actúa la Deyanira de Sófocles, y estudia igualmente los paralelismos entre Altea y Deyanira (la discusión sobre Meleagro y Heracles en Baquílides se encuentra en las pp.34-36); Faraone (1994), para quien el error de Deyanira no es ignorar la existencia del veneno, sino desconocer sus efectos fatales o advertirlos demasiado tarde (vv.714-716); Ryzmak (1991), quien piensa que quizá Deyanira sea una mujer inocente, pero ciertas ambigüedades sugieren que su carácter no es en absoluto simple; Carawan (2000), para quien Deyanira no actúa con intención de matar a Heracles, aunque sepa que su magia es peligrosa para su marido, pero en todo caso es culpable a los ojos del público ateniense porque ha usado magia erótica que ha acabado con la vida del héroe, aunque no fuera ése el resultado que ella buscaba (en las páginas 191 ss. se estudia el carácter amazónico original de Deyanira, y en 197 ss. concluye que la Deyanira «asesina involuntaria» existía ya al menos una generación antes de Sófocles y esa tradición sería recogida por Baquílides en su ditirambo 16, que no depende de Sófocles). Cf. Cummins (1993: 266 ss.), quien afirma (a mi entender de manera errónea) que también en Baquílides 16 se dice que Deyanira mató intencionadamente a Heracles.

${ }^{52}$ Sobre las semejanzas entre Medea y Deyanira, cf. Davies (1989); Segal (1975: 38) y (1981: 72-73); Bañuls \& Crespo (2006: 31 ss.). 
explique por qué Baquílides no sigue para la muerte de Meleagro la versión épica de Homero (quizá), Hesíodo y la Miníada ${ }^{53}$ (según la cual Meleagro muere a manos de Apolo, como consecuencia de la maldición lanzada contra él por Altea), sino que es la propia Altea quien causa directamente la muerte de su hijo utilizando, como hará Deyanira, un procedimiento más o menos mágico: quemando el tizón al que estaba ligado el destino de Meleagro, una versión que, según el testimonio de Pausanias (X 31, 4), seguía ya Frínico en su tragedia Las mujeres de Pleurón (fr.6 Snell-Kannicht) y que se ha propuesto remontar hasta Los cazadores del jabali de Estesícoro ${ }^{54}$ (quizá se encuentre también en el fr. 70d Maehler de Píndaro).

En definitiva, en el mito del epinicio 5 de Baquílides lo que un personaje del relato, Heracles, considera con cierto optimismo (su futura boda con la hermana de Meleagro), mediante el uso de la ironía dramática se le recuerda a los espectadores que ese mismo hecho va a ser la ruina del héroe, cuyo destino terminará siendo similar al del propio Meleagro. Se podría hablar, entonces, de un final «pesimista», pero quiero dejar claro que hablo siempre de «pesimismo» en el relato mítico y no de pesimismo en el epinicio en su conjunto ${ }^{55}$, pues estoy plenamente de acuerdo con quienes opinan que el poeta no puede transmitir un mensaje «pesimista» a un vencedor olímpico al que ha comenzado

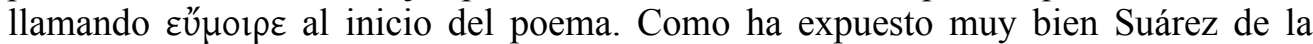

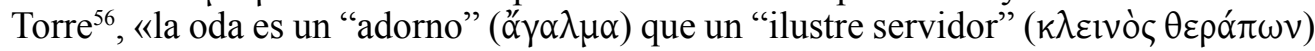
de la Musa Urania ha enviado para "alabar" ( $\alpha i v \varepsilon i v v)$ a Hierón..., que es descrito como "feliz" (ó $\lambda \beta 10 \zeta$, v.50; es el único personaje no mítico al que Baquílides califica con ese epíteto). En este contexto, el mito de Meleagro no puede contener ningún tipo de

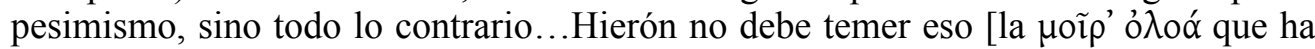
arruinado a los personajes del mito]. Al comienzo mismo del epinicio (v.1) Hierón ha

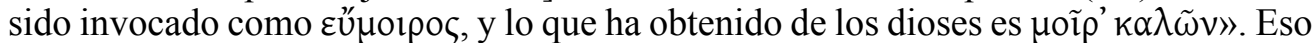
se nos dice, en efecto, en la sentencia de transición al mito (vv.50 ss.), donde además Hierón es calificado como ő $\lambda ß$ ı̌c. Así pues, Baquílides establece una oposición entre la felicidad de Hierón, fruto del favor divino, y la desgracia de los personajes del mito, obra también de los dioses, de manera que para el destinatario del poema el mito de Meleagro y Heracles es un «ejemplo negativo», que ilustra la felicidad de Hierón insistiendo en las diferencias que lo separan de los personajes del mito (del mismo modo que la ingratitud de Ixión en la Pítica II de Píndaro sirve de contraste negativo para la gratitud de Hierón). Pero, obviamente, Baquílides no exalta la felicidad de Hierón sin ningún tipo de restricciones. Hay un límite, y es la inestabilidad de toda situación humana, en particular el éxito y la felicidad. Baquílides, en efecto, ilustra la buena fortuna de Hierón por contraste con la desgracia de los personajes del mito, pero al mismo tiempo recuerda a Hierón que la felicidad puede trocarse en desgracia, como sugieren, por ejemplo, las alusiones al trágico final de Heracles que hemos comentado.

${ }^{53} \mathrm{Il} .9 .566$ ss. (no se alude expresamente a la muerte de Meleagro, pero parece que subyace la versión de Hesíodo); Hes. fr.25.12-13; Miníada, fr. 5 y 7 Bernabé.

${ }^{54}$ Cf. al respecto March (1987: 43 ss.), Bremmer (1988), Suárez de la Torre (2000: 82-83 nota 45), Renaud (1993) y (2000).

${ }^{55}$ Cf. Stern (1967), Lefkowitz (1969: 92).

${ }^{56}$ Suárez de la Torre (2000: 82-83); cf. García Romero (2002: 172 ss.). 
Sólo así se entiende plenamente que en las sentencias que sirven de transición al mito se diga que «ninguno de los mortales ha nacido feliz en todo» (vv.53-55) y sólo así se entiende que el poeta finalice su poema expresando su deseo de que la felicidad de Hierón continúe en el futuro: «pues así florecen las raíces de los bienes, los cuales el supremo padre Zeus ojalá conserve inmutables en paz» (vv.197-200) ${ }^{57}$.

El mismo procedimiento de la «ironía dramática» es usado en el ditirambo 18, precisamente en sentido opuesto a lo que hemos visto en el mito del epinicio 5: al rey Egeo y al coro de atenienses les llegan noticias sobre las increíbles hazañas de un joven, unas noticias que Egeo y los atenienses interpretan como una potencial amenaza para Atenas (vv.1 ss., 30, 60); pero el espectador sabe que ese joven va a ser precisamente la gloria de Atenas ${ }^{58}$. También este poema concluye con un final abrupto $\mathrm{y}$ alusivo, y es que esta forma alusiva de narrar reaparece continuamente en el género más «narrativo» que cultiva nuestro poeta, el ditirambo, y de hecho los ditirambos 15 , 16 y 18 acaban de manera abrupta y alusiva a un futuro que los personajes ignoran y en cambio los espectadores conocen. Para el tema que hemos tratado es especialmente interesante el caso del ditirambo 16, ya que trata la historia de Heracles y Deyanira y acaba también con una alusión irónica a la muerte del héroe ${ }^{59}$; y precisamente el carácter fuertemente alusivo del poema (el uso de la «ironía dramática») se ha utilizado como argumento para defender la hipótesis de que el ditirambo es posterior a Las traquinias de Sófocles, pues sólo con el conocimiento previo de la versión trágica podría haber entendido el público las alusiones del poema de Baquílides, quien sigue efectivamente la misma versión que Sófocles ${ }^{60}$. Y no sería la única influencia trágica en este ditirambo. Diversos autores han señalado que Heracles y Deyanira en el poema 16 (al igual que Heracles, Altea y Meleagro en el epinicio 5) son retratados por nuestro poeta como figuras trágicas, ignorantes de su futuro y que actúan libremente pero a la vez no pueden eludir su destino (su acción es mezcla de su propia decisión y de un daimon: cf. vv. 113, 121 y 143 del epinicio 5) ${ }^{61}$.

${ }^{57}$ Svarlien (1995) nota el contraste entre el significado negativo de las imágenes vegetales en el relato mítico y su valor positivo en las partes no míticas dedicadas a Hierón.

${ }^{58}$ Cf. Burnett (1985: 122-123).

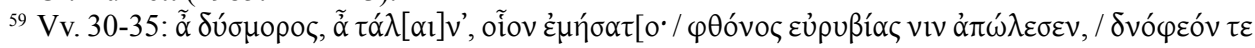

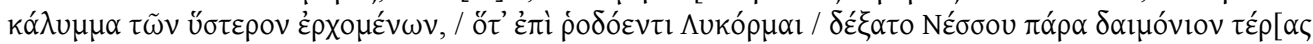
( «iAh, desventurada! ¡Ah, desgraciada! ¡qué cosa planeó! Los celos de amplia fuerza la perdieron, y también tenebroso velo de lo que vendría después, cuando en el róseo Licormas recibió de manos de Neso el prodigio fatal»).

${ }^{60}$ Schwinge (1962: sobre todo 128-133), Hoey (1979), March (1987: 62 ss.), Maehler (1997: 155-156), Pfeijffer (1999). En cambio, Gentili (1958: 49-58) defiende la influencia de Baquílides sobre Sófocles. Cf. también Nelli (2006).

${ }^{61}$ Cf. Burnett (1985: 126, 146); March (1987: 62 ss.); Segal (1990); Pfeiffer (1999: 53 ss.); Brioso \& Villarrubia (1989); Platter (1994). 


\section{BIBLIOGRAFÍA}

Bañuls, José V. \& Crespo, Patricia (2006), «La imposible Medea de Sófocles», en F. de Martino (ed.), Medea. Teatro e comunicazione, Bari: 23-66.

BARrett, William S. (1964), Euripides. Hippolytos, Oxford.

BARrigón, Carmen (2003), «Simónides de Ceos y su concepción poética», en E. Suárez de la Torre (coord.), Teoría y práctica de la composición poética en el mundo antiguo y su pervivencia, Valladolid: 25-67.

Bernardini, Paola A. (1980), «Essaltazione e critica dell'atletismo nella poesia greca dal vir al v secolo a.C. Storia di un'ideologia», Stadion 6: 81-111.

Bowra, Cecil M. (1964), «The athletic ideal», en Pindar, Oxford: 159-191.

Brannan, Patrick T. (1972), «Hieron and Bacchylides. An analysis of Bacchylides' fifth ode», CF 26: $185-278$.

Bremmer, Jan (1988), «La plasticité du mythe: Méléagre dans la poésie homérique», en C. Calame (ed.), Métamorphoses du mythe en Grèce antique, Genève: 37-56.

Brioso, Máximo \& Villarrubia, Antonio (1989), «Dos notas a Baquílides (XVI 31 y XIX 11)», Habis 20: 17-19.

Burnett, Ann P. (1985), The art of Bacchylides, Cambridge (Mass.).

Calame, Claude (2002), Eros en la antigua Grecia, Madrid.

CARAwan, Edwin (2000), «Deianira's guilt», TAPhA 130: 189-237.

CAREY, Christopher (1999), «Ethos and pathos in Bacchylides», en I. Pfeijffer \& S.R. Sling (eds.), One hundred years of Bacchylides, Amsterdam: 17-29.

CARne-Ross, Donald S. (1962), «The gaiety of language», Arion 1: 65-88.

Cassanello, Maria Teresa (1993), Lessico erotico della tragedia, Roma.

Chantraine, Pierre (1956), Études sur le vocabulaire grec, Paris.

- (1968), Dictionnaire étymologique de la langue grecque. Histoire des mots, Paris.

Croiset, Alfred (1898), «Bacchylide», REG 11: 6-16.

Cummins, Monessa F. (1993), Myth in Pindar and Bacchylides: five studies in narrative pattern and convention, Ann Arbor.

DAvies, Malcolm (1989), «A foot-note to the Pre-history of two myths», Mnemosyne 42: 469-472.

Del Grande, Carlo (1956), Filologia Minore, Milano.

- $\left(1963^{3}\right)$, Phórminx. Antologia della lirica greca, Napoli.

Douterelo, Esther (1997), «El léxico y el tema del amor en Las traquinias de Sófocles», CFC(egi) 7: 195-206.

Easterling, Patrick \& Knox, Bernard M.W. (eds.) (1995), Cambridge History of Classical literature, Cambridge.

EdMonds, John M. (1927), Lyra Graeca, London.

ERRANDONEA, Ignacio (1927), «Deianira uere DHI-ANEIRA», Mnemosyne 55: 145-164.

FARAone, Chistopher A. (1994), «Deianira's mistake and the demise of Heracles: erotic magic in Sophocles' Trachiniae», Helios 21: 115-135.

FARAone, Christopher A. (1999), Ancient Greek love magic, London.

FEArn, David (2007), Bacchylides. Politics, performance, poetic tradition, Oxford.

Fernández Colinas, Pedro (1994), Los términos de color en la poesía de Teócrito, tesis de la Universidad Complutense de Madrid. 
Fernández Galiano, Manuel (1971), «El sentido del deporte en Píndaro», Citius Altius Fortius 13: $121-140$.

FINN, James K. (1980), A study of the elaboration and function of epinician conventions in selected odes of Bacchylides, Dis. Duke Univ.

FrISK, Hjalmar (1960-1972), Griechisches etymologisches Wörterbuch, Heidelberg.

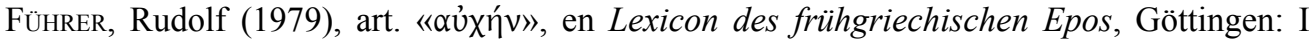
1685-1687.

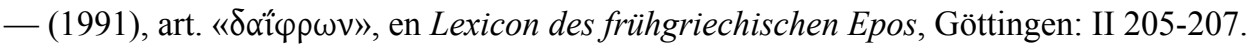

García Romero, Fernando (1987), Estructura de la oda baquilidea. Estudio composicional y métrico, Madrid.

- (1992), «Poesía y deporte en la antigua Grecia», Revista de Occidente 134-135: 45-60.

- (2002), «La función del mito en el epinicio», en J.A. López Férez (ed.), Mitos en la literatura griega arcaica y clásica, Madrid: 159-174.

Gentili, Bruno (1958), Bacchilide. Studi, Urbino.

Gerber, Douglas E. (1984), Lexicon in Bacchylidem, Hildesheim-Zürich-New York.

Goldhill, Simon (1983), «Narrative structure in Bacchylides 5», Eranos 81: 65-81.

Gómez SEgura, Eugenio (1994), «Reflejos culturales de la percepción: vocabulario del tacto en Teócrito», Minerva 8: 139-147.

Handschur, Erna (1970), Die Farb- und Glanzwörter bei Homer und Hesiod, in den homerischen Hymnen und den Fragmenten des epischen Kyklos, Wien.

Hoey, Thomas F. (1979), «The date of the Trachiniae», Phoenix 33: 210-232.

Hunter, Richard L. (1989), Apollonius of Rhodes. Argonautica, book III, Cambridge.

Hutchinson, Gregory O. (2001), Greek lyric poetry, Oxford.

Irigoin, Jean, Duchemin, Jacqueline \& Bardollet, Louis (1993), Bacchylide. Dithyrambes, Épinicies, Fragments, Paris.

InwIN, Eleanor (1974), Colour terms in Greek poetry, Toronto.

Jebi, Richard C. (1892), Sophocles. Trachiniae, Cambridge (reimp. 1962).

JEBB, Richard C. (1905), Bacchylides. The poems and fragments, Cambridge.

JAX, Karl (1933), Die weibliche Schönheit in der griechischen Dichtung, Innsbruck.

Kamerbeek, Jan C. (1970), Sophocles. The Trachiniae, Leiden.

KIRKWOOD, Gordon M. (1966), «The narrative art of Bacchylides», en L. Wallach (ed.), The classical tradition. Literary and historical studies in honor of H. Caplan, Ithaca: 98-114.

KRIEGLER, Helga (1969), Untersuchungen zu den optischen und akustischen Daten der bakchylideischen Dichtung, Wien.

Lasso de la Vega, José (1977), «Repeticiones verbales en la Nemea Séptima», Helmantica 28: 281-294.

Lefkowitz, Mary R. (1969), «Bacchylides' Ode 5, imitation and originality», HSCPh 73: 45-96. - (1976), The victory ode. An introduction, Park Ridge.

LORENZONI, Alberta (1994), «Eustazio: paura "verde" e oro "pallido"», Eikasmos 5: 139-163.

MAEHLER, Herwig (1982), Die Lieder des Bakchylides. I: Die Siegeslieder, Leiden (reimpr. 1997).

- (1997), Die Lieder des Bakchylides. II: Dithyramben und Fragmente, Leiden.

MALLINGer, Louis (1899) «Le caractère, la philosophie et l'art de Bacchylide», Musée Belge 3: 21-49.

MANIERI, Alessandra (1990), «La terminologia “mimetica” in Simonide», Rudiae 2: 77-102. 
MARCH, Jennifer R. (1987), The creative poet, London.

Morin, Bertrand (2007), «Du tison au flocon: Méléagre et l'Héraclès des Trachiniennes», AC 76: $25-38$.

Mrose, Herman (1902), De syntaxi Bacchylidea, Dis. Leipzig.

MüLler, Heinz M. (1980), Erotische Motive in der griechischen Dichtung bis auf Euripides, Hamburg.

Nelli, María Florencia (2006), «El mito de Heracles en Baquílides: su relevancia para el análisis de las Traquinias de Sófocles», Síntesis 13: 79-83.

PÉrez, Brigitte (2000), «La magie d'Éros», en A. Moreau \& J.C. Turpin (eds.), La magie, Montpellier: I 293-306.

PÉron, Jacques (1978), «Les mythes de Crésus et Méléagre dans les Odes III et V de Bacchylide», REG 91: 307-339.

Pfeijffer, Ilja L. (1999), «Bacchylides’ Homer, his tragedy, and his Pindar», en I. L. Pfeijffer \& S.R. Sling (eds.), One hundred years of Bacchylides, Amsterdam: 43-60.

- (2004), «Pindar and Bacchylides», en I. De Jong, R. Nünlist \& A. Bowie (eds.), Narrators, narratees and narratives in ancient Greek literature, Leiden: 213-232.

Pfeijffer, Ilja L. \& Slings, Simon R. (eds.) (1999), One hundred years of Bacchylides, Amsterdam.

Pietsch, Christian (2003), «Einheit oder bunte Fülle? Zu Funktion und Integration des Mythos in den Epinikien des Bakchylides am Beispiel des Herakles-Meleager-Mythos in B.5», en D. Accorinti \& P. Chuvin (eds.), Des Géants à Dionysos: mélanges de mythologie et de poésie grecques offerts à Francis Vian, Alessandria: 173-188.

Plácido, Domingo (1994), «Los celos de Deyanira», en J. Alvar (ed.), Sexo, muerte y religión en el mundo clásico, Madrid: 11-16.

Platter, Charles (1994), «Heracles, Deianeira, and Nessus: reverse chronology and human knowledge in Bacchylides 16», AJPh 115: 337-350.

Pozzi, D.C. (1996), «Deianira vere Oenei filia», Hermes 124: 104-108.

Renaud, Jean M. (1993), Le mythe de Méléagre. Essais d'interprétation, Liège.

- (2000), «Magie et imprécations dans les mythes grecs: le cas d'Althaia», en A. Moreau \& J.C. Turpin (eds.), La magie, Montpellier: III 223-231.

Rengakos, Antonios (2000), «Zu Bakchylides’ Erzähltechnik», en A. Bagordio \& B. Zimmermann (eds.), Bakchylides. 100 Jahre nach seiner Wiederentdeckung, München: 101-112.

RESINSKI, Rebecca (2000), «Deianeira's neck in Bacchylides, Ode 5», Helios 27: 3-14.

RobBins, Emmet (1997), «Bacchylides», en D.E. Gerber (ed.), A companion to the Greek lyric poets, Leiden-New York-Köln: 278-287.

Rossi, Luigi E. (1995), Letteratura greca, Firenze.

Rutherford, Ian (1997), "Odes and ends: closure in Greek lyric», en D.H. Roberts, F.M. Dunn \& D. Fowler (eds.), Classical closure. Reading the end in Greek and Latin literature, Princeton: 43-61.

RYzMAK, Marlene (1991), «Deianeira's moral behaviour in the context of the natural laws in Sophocles' Trachiniae», Hermes 119: 385-398.

Schwinge, Ernst R. (1962), Die Stellung der Trachinierinnen im Werk des Sophokles, Göttingen.

Segal, Charles (1975), «Mariage et sacrifice dans les Trachiniennes de Sophocle», AC 44: $30-53$. 
- (1976), «Bacchylides reconsidered. Epithets and the dynamics of the lyric narrative», QUCC 22: 99-130 (= Aglaya. The poetry of Alcman, Sappho, Pindar, Bacchylides and Corinna, Lanham 1998: 251-279).

- (1981), Tragedy and civilization. An interpretation of Sophocles, Cambridge-London.

- (1990), «Sacrifice and violence in the myth of Meleager and Heracles: Homer, Bacchylides, Sophocles», Helios 17: 7-24.

Schadewaldt, Wolfgang (1928), Der Aufbau des pindarisches Epinikion, Halle.

STEFFen, Viktor (1961), «Bacchylides' fifth ode», Eos 51: 11-20

STERN, Jacob (1967), «The imagery of Bacchylides' Ode V», GRBS 8: 35-43.

- (1970), «An essay on Bacchylidean criticism», en W. Calder \& J. Stern (eds.), Pindaros und Bakchylides, Darmstadt: 290-307.

Stoessl, Franz (1945), Der Tod des Heracles, Zürich.

SuÁrez de la Torre, Emilio (1988), «Baquílides», en J.A. López Férez (coord.), Historia de la literatura griega, Madrid: 226-231.

- (2000), «Bemerkungen zu den Mythen bei Bakchylides», en A. Bagordio \& B. Zimmermann (eds.), Bakchylides. 100 Jahre nach seiner Wiederentdeckung, München: 69-85.

SvARLIEN, Diane A. (1995), «Reversal of imagery and values in Bacchylides 3 and 5», QUCC 50: $35-45$.

Taccone, Angelo (1907), Bacchilide. Epinici, ditirambi e frammenti, Torino.

VAN Groningen, Bernhard A. (1960²), La composition littéraire archaïque grecque, Amsterdam.

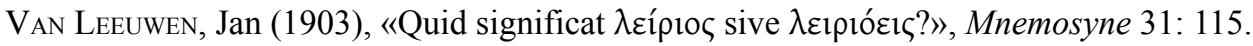

Wulff Alonso, Fernando (1997), La fortaleza asediada. Diosas, héroes y mujeres poderosas en el mito griego, Salamanca. 